\title{
FAILURE OF THERMOPLASTIC COMPOSITE WELDED JOINTS
}

\author{
Bas H.A.H. Tijs ${ }^{1,3 *}$, Albert Turon ${ }^{2}$ and Chiara Bisagni ${ }^{3}$ \\ ${ }^{1}$ GKN Aerospace Fokker, Papendrecht, The Netherlands \\ 2 AMADE, Polytechnic School, University of Girona, Universitat de Girona 4, Girona, Spain \\ ${ }^{3}$ Delft University of Technology, Faculty of Aerospace Engineering, Delft, The Netherlands \\ *bas.tijs@fokker.com
}

This presentation summarizes the numerical and experimental evaluation of the failure behavior of thermoplastic composites, which are joined by means of conduction welding. The research supports the development of a next generation thermoplastic multi-functional fuselage [1]. The use of these new materials and fastener-free joints introduces new challenge as the strength of the welded joint is highly dependant on the strength and failure behavior of the thermoplastic matrix. A simplified modelling strategy that only accounts for a cohesive zone at the weld is compared to a high-fidelity model that takes into account the physical failure mechanisms at the lamina level. It was found that the joint strength is highly influenced by the failure mechanisms of not only the welded interface but also the surrounding plies. The high-fidelity modelling methodology is able to predict the failure mode of these welded joints with high accuracy with respect to the results obtained experimentally as shown in Figure 1.

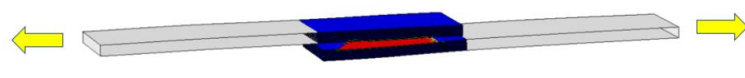

Conduction welded single lap shear joint
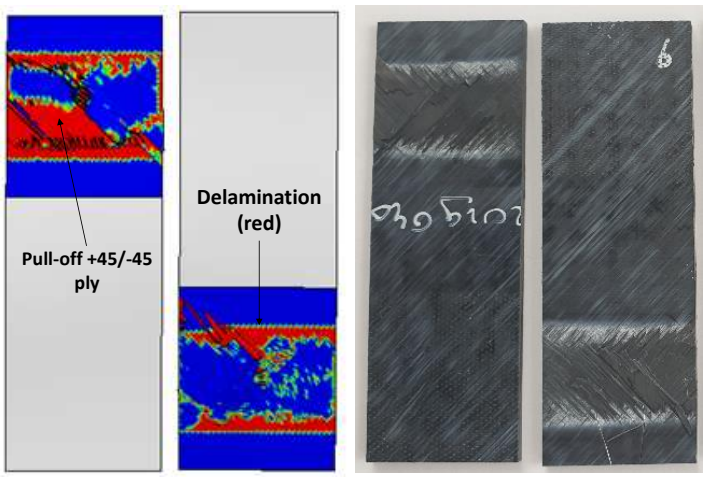

Numerical (left) vs Experimental (right) failure mode

Figure 1. Numerical and experimental failure mode of conduction welded single lap shear joint

The work received co-funding from the Clean Sky 2 Joint Undertaking under the European Union's Horizon 2020 research and innovation programme under grant agreement No 776455.

\section{References}

[1] B.H.A.H. Tijs, K.S. van Dooren and C. Bisagni (2020) Development of a numerical framework for virtual testing to support design of a next generation thermoplastic multifunctional fuselage. Proceedings of the European Conference on Multifunctional Structures (EMuS2020). 